\title{
Journal of \\ Diabetes and Obesity

\section{Insulin Resistance, Impaired Fasting, Glucose Intolerance and Type II Diabetes Mellitus in Overweight and Obese Children in Abu Dhabi}

\author{
Deeb Asma $^{\text {1* }}$ Attia Salima ${ }^{1}$, Mahmoud Samia $^{2}$, Elhaj Ghada ${ }^{3}$, Elfatih Abubaker $^{4}$ \\ ${ }^{1}$ Pediatric Endocrinology Department, Mafraq Hospital, P O Box 2951, Abu Dhabi, United Arab Emirates \\ ${ }^{2}$ Pediatric Clinic, Police Health Services, Abu Dhabi \\ ${ }^{3}$ Baniyas Healthcare Centre, Abu Dhabi \\ ${ }^{4}$ Biochemistry Department, Mafraq Hospital, Abu Dhabi
}

*Corresponding author: Dr. Asma Deeb, Pediatric Endocrinology Department, Mafraq Hospital, P O Box 2951, Abu Dhabi, United Arab Emirates, Tel: +971-50-8350568; Fax: +971-2-5012199; E-mail: adeeb@mafraqhospital.ae

\begin{abstract}
Background: Obesity is increasingly seen in children and youth. It is linked to major health concerns including glucose intolerance and type II diabetes. This study aims to assess the prevalence of impaired glucose tolerance, impaired fasting, and insulin resistance and type $2 \mathrm{DM}$ in overweight and obese children and adolescents presenting to our pediatric endocrinology clinic in Abu Dhabi, UAE.

Methods: Overweight and obese children and adolescents are enrolled in an observational, cross-sectional study. Patients had detailed demographic and family history taken. Standardized weight, height, BMI and waist circumference were recorded. Laboratory tests included fasting glucose, insulin and $\mathrm{HbAlc}$ were done. Patients who had high fasting glucose or HbAlc had standard oral glucose tolerance test. Insulin sensitivity was assessed by applying HOMA-index.

Results: A total of 216 patients (121 males) were enrolled; mean age was $10.58 \pm 2.9$ years. $93 \%$ were obese, $7 \%$ overweight; and 173 had a waist circumference $\geq 90^{\text {th }}$ centile. 147 patients $(74.2 \%)$ were insulin resistant; 7 patients were diagnosed with diabetes $(6$ had $\mathrm{HbAlc}$ above $6.5,1$ had 2 consecutive glucose measurements above $7 \mathrm{mmol} / \mathrm{L}$ ), and 87 (43.5\%) had an indication for OGTT: 26 elevated fasting, 50 elevated HbA1c, and 11 had both. 15 patients $(8.2 \%)$ had impaired glucose tolerance and 37 (18.1) had impaired fasting. 5 patients of 11 with impaired fasting and elevated Hbalc (45.5\%) and 8 patients of 50 elevated $\mathrm{HbA1c}(17.4 \%)$ had glucose intolerance.

Conclusions: Insulin resistance is common in overweight and obese children and is more commonly seen in older children with high weight, height and waist circumference. Higher yield of glucose intolerance is obtained when screening utilized combination of high fasting glucose and $\mathrm{HbA1c}$.
\end{abstract}

Received date: : March 02, 2017

Accepted date: April 28, 2017

Published date: May 08, 2017

Citation: Deeb, A., et al. Insulin Resistance, Impaired Fasting, Glucose Intolerance and Type II Diabetes Mellitus in Overweight and Obese Children in Abu Dhabi. (2017) J diab Obes 4(2): 1- 8.

DOI: $10.15436 / 2376-0494.17 .1389$

Keywords: Type II diabetes mellitus; Glucose intolerance; Insulin resistance; Hyperinsulinism; Impaired fasting; Adolescents and children; Abu Dhabi

\section{Introduction}

Obesity is an increasing health concern worldwide. It is strongly linked to morbidity and mortality through its associated health risks. Major associations of obesity are glucose intolerance and Type II diabetes mellitus which are linked to a number of nutritional and environmental factors. It has been reported that death attributable to diabetes accounted for $2 \%-3 \%$ of all deaths in the UAE in the last ten years ${ }^{[1]}$. Sedentary life style has led to the emergence of obesity and metabolic syndrome at a much younger age compared to the past. This has been the case around the world and the Arab countries, particularly the Gulf $\operatorname{area}^{[1]}$.

Childhood obesity in the Gulf and some other regions around the world has dramatically increased to reach an epidemic proportion ${ }^{[2]}$. In the USA, the number of overweight children has more than doubled and childhood obesity has shown a rapid increase in countries like the $\mathrm{UK}^{[3]}$.

Data from the Health Authority of Abu Dhabi showed a prevalence of childhood obesity reaching up to $30 \%$ in school children ${ }^{[4]}$.

With the increasing prevalence of obesity, various forms of co-morbidities are seen in children including glucose 
intolerance, insulin resistance, dyslipidaemia and fatty liver disease $^{[5,6]}$.

Epidemiological studies have shown a high prevalence of Type II diabetes among the Arab population of various Gulf countries; Oman ${ }^{[7]}$, Saudi Arabia ${ }^{[8]}$ and Kuwait ${ }^{[9]}$. The ministry of Health in Dubai, UAE and the World Health Organization (WHO) conducted a national diabetes survey on the population of the UAE in 2000. The study revealed that almost a quarter of the population in the UAE had diabetes ${ }^{[10]}$.

In the past, type 2 diabetes has not been a problem of young people, however, over the last two decades; type 2 diabetes has been emerging as a global public health problem in children and adolescents ${ }^{[11-14]}$. The disease is emerging among children all around the world including the Gulf region.

The SEARCH study for diabetes among children and adolescents below 20 years of age revealed that both type 1 and type 2 diabetes mellitus are frequent and on the rise among U.S youth in a majority of racial and ethnic populations, sex and age groups. $15.9 \%$ of the children diabetes population was of type 2 diabetes. A proportion within type 1 diabetes patients had associated insulin resistance due to obesity ${ }^{[15]}$. At the local level in the UAE, $10 \%$ of children diagnosed with diabetes were found to have had type $2 \mathrm{DM}$ in the city of Al Ain ${ }^{[16]}$. Similarly, 9\% of children diagnosed with diabetes in Dubai are found to have type II diabetes. This was out of 304 school age children (4 - 19 years) diagnosed with diabetes by specialist clinics in Department of Health and Medical Services ${ }^{[17]}$.

The trend of the growing incidence of type 2 diabetes in children follows in other parts of the Gulf region. In a study of 6 - 18 years old Kuwaiti school children, type 2 diabetes was identified in 45 of the 128,918 children studied for an overall prevalence of 34.9 per 100,000 population ${ }^{[18]}$. Another study perceived childhood obesity and type 2 diabetes as a growing public health challenge in UAE, given the sharp rise in obesity-induced type 2 diabetes among UAE youth. The study speculated that diabetes is set to affect half the UAE population in the next two decades if the present lifestyle trends continue ${ }^{[19]}$.

In 2012, a retrospective cross-sectional study on 387 overweight and obese pediatric patients between the ages of 2 and 18 years recruited between the years 2006 and 2010 in a center in Saudi Arabia, showed that $44 \%$ of this population had hyperinsulinism, and 9 percent had type II diabetes ${ }^{[20]}$.

Increasing incidence of type II diabetes in children is multifactorial but it is directly linked to the increased incidence of obesity, which in turn is driven by a general decline in physical activity and increased reliance on fast and processed food. In 2013, a cross-sectional study conducted in Kuwait showed that 20 to $58 \%$ of male and female adolescents were overweight or obese $^{[21]}$.

A single important factor is that most overweight children have diminished exercise tolerance which is a compounding factor to failure of weight control and a start of a vicious cycle of increased weight and development of glucose intolerance and even overt diabetes mellitus.

In the UAE in particular, an additional factor is the wide use of television, hand-held electronic game devices and computers $^{[2]}$.

There are various geographical and ethnic variations in the prevalence of type II diabetes worldwide. Considering the high rate of obesity in children and the high prevalence of type II in our region, it is important to study the disease and its co-morbidities in the region. Assessing the extent and the impact of the problem is of paramount importance in planning of prevention strategies in youths.

This study aims to assess the prevalence of impaired glucose tolerance, impaired fasting, insulin resistance and type 2 DM in overweight and obese children and adolescents presenting to our pediatric endocrinology clinic in Abu Dhabi, UAE.

\section{Methods}

\section{Participants and setting}

This study is observational, descriptive cross-sectional, intending to investigate the prevalence of multi-variables in an obese population. All patients meeting the inclusion criteria and none of the exclusion criteria and attending the Paediatric Endocrinology department, Mafraq hospital, Abu Dhabi during the period between October 2013 and October 2015 were approached to take part in the study; a total of 216 approved.

Inclusion criteria for enrollment were school children between the ages of 4 and 19 years who were referred to the endocrine clinic for obesity assessment and management. Children recruited were either overweight or obese with a BMI centile above the $85^{\text {th }}$ or $95^{\text {th }}$ respectively.

Children with the above criteria were approached to participate in the study. The aim and the procedure of the study were explained to the children and parents and they were given a study information leaflet to read. Those who agreed to participate gave assents and parents/guardians signed a consent form.

Children diagnosed with hormonal disorders; diabetes, hypothyroidism or polycystic ovarian syndromes were excluded from the study. Moreover, patients on long term use of corticosteroids or anti-epileptic medication were also excluded.

The research study was approved by the Research Ethics Committee at Mafraq hospital, Abu Dhabi, UAE.

\section{Measures}

All patients participating in the study were interviewed by one of 2 pediatric endocrinologists. Case report forms included information on demographics, and family history, namely history on diabetes, obesity, dyslipidemia, and cardiovascular diseases in a first degree relative. Physical exams of patients included height, weight, waist circumference and assessment of acanthosis nigricans. Blood pressure was taken twice and the average was calculated for systolic and diastolic pressure. BMI was calculated as weight/height ${ }^{2}$ and plotted on BMI chart to determine the centile.

Standardized BMI, BP, height and weight for age z-scores were calculated based on the CDC growth charts ${ }^{[23]}$ while standardized waist circumference scores were generated based on the Jackson RT et al study for waist circumference percentile in Kuwaiti children and adolescents ${ }^{[24]}$.

Blood tests performed were fasting blood glucose (FBG), fasting insulin, and $\mathrm{HbA1c}$. Children with elevated $\mathrm{HbA} 1 \mathrm{c}$ assessed as $5.7 \% \leq \mathrm{HbA} 1 \mathrm{c}<6.5 \%$ or high fasting blood glucose assessed as $5.6 \mathrm{mmol} / \mathrm{L} \leq \mathrm{FBG}<7 \mathrm{mmol} / \mathrm{L}$ had a standard oral glucose tolerance test. Impaired glucose tolerance was diagnosed if 2 hours blood glucose was $\geq 7.8 \mathrm{mmol} / \mathrm{L}$. Insulin resistance was measured by applying the HOMA-IR formula utilizing fasting insulin and fasting glucose $\mathrm{e}^{[25]}$. All patients having 
HOMA-IR score $\geq 3$ were considered having insulin resistance. Patients having $\mathrm{HbA} 1 \mathrm{c}>6.5 \%$ or two consecutive measures of $\mathrm{BG}>7 \mathrm{mmol} / \mathrm{L}$ were considered diabetic ${ }^{[26]}$.

\section{Power calculation}

The power for the study is calculated to estimate prevalence of impaired glucose tolerance, impaired fasting, insulin resistance and type $2 \mathrm{DM}$ with 95\% confidence level and 0.1 absolute precision. To obtain the maximum value for minimum sample size, the proportion of outcomes was set at $50 \%$ in the target population. According to the above criteria, the minimum sample size was found to be 97 .

\section{Statistical analysis}

Descriptive statistics means and standard deviations were used to analyze continuous parameters. Frequencies and percentages were used to analyze categorical parameters. Bivariate logistic regressions were performed to determine the relationship between impaired glucose tolerance, insulin resistance, type II DM and impaired fasting with age, gender, BMI, height, weight, waist conference and blood pressure. A two-tailed p-value was computed and significance was set at p-value less than 0.05 .

Statistical analysis was performed using IBM SPSS software version 23.

\section{Results}

216 patients were enrolled in the study; $121(56.0 \%)$ were males and $95(44.0 \%)$ females. The overall age of the sample ranged between 4 and 19 years. Mean \pm SD age was 10.58 \pm 2.996 years. Standardized mean \pm SD for height was $0.44 \pm$ 1.195 while that for weight was $2.30 \pm 0.704 .15$ (7.0\%) of children were overweight, $201(93.0 \%)$ were obese with a BMI $\geq$ $95^{\text {th }}$ percentile.

A total of 138 (63.9\%) of patients had acanthosis nigricans. The standardized mean \pm SD for waist circumference was $2.31 \pm 1.058 \mathrm{cms} .173$ patients $(89.6 \%)$ had a $\mathrm{WC} \geq 90^{\text {th }}$ percentile. The standardized mean \pm SD for systolic blood pressure was $1.10 \pm 1.014 \mathrm{mmHg}$ while that for diastolic blood pressure was $0.55 \pm 0.812 \mathrm{mmHg}$.

$80 \%$ of the patients had a family history of obesity and $79.4 \%$ had a family history of diabetes. $55.5 \%$ had a family history of hyperlipaedemia and a total of $40.7 \%$ had a family history of cardiovascular diseases (table 1). 147 patients $(74.2 \%)$ were insulin resistant and 62 patients $(31.0 \%)$ had elevated HbAlc $(5.7 \% \leq \mathrm{HbA} 1 \mathrm{c}<6.5 \%) .87(43.5 \%)$ had an indication for OGTT of either elevated fasting glucose (26), elevated HbA1c (50) or both (11). Out of the 87, 78 (89.7\%) had OGTT.

A total of $7(3.5 \%)$ patients were diagnosed with diabetes; $6(85.7 \%)$ had HbA1c at or above $6.5 \%, 3(42.9 \%)$ had fasting blood glucose at or above $7 \mathrm{mmol} / \mathrm{L}$ of which 1 patient had 2 consecutive measures of fasting blood glucose above diabetes range. Among all non-diabetics $(\mathrm{n}=209), 37$ patients $(18.1 \%)$ had impaired fasting while $15(8.2 \%)$ had impaired glucose tolerance (table 2).
Table 1: Sample Characteristics.

\begin{tabular}{|c|c|c|c|}
\hline & & $\begin{array}{l}\text { Frequency } \\
(\%)\end{array}$ & Mean (SD) \\
\hline \multirow{2}{*}{ Demographics } & Gender (Males) & $121(56.0)$ & \\
\hline & Age $($ Mean \pm SD) & & $10.58(2.996)$ \\
\hline \multirow{9}{*}{$\begin{array}{l}\text { Physical } \\
\text { Exam }\end{array}$} & $\begin{array}{l}\text { Height-for-age } \\
(\text { Mean } \pm \text { SD) }\end{array}$ & & $0.44 \pm 1.195$ \\
\hline & $\begin{array}{l}\text { Weight-for-age } \\
(\text { Mean } \pm \text { SD) }\end{array}$ & & $2.30 \pm 0.704$ \\
\hline & $\begin{array}{l}\text { WC-for-age } \\
(\text { Mean } \pm \text { SD) }\end{array}$ & & $2.31 \pm 1.058$ \\
\hline & $\begin{array}{l}\mathrm{WC} \geq 90^{\text {th }} \\
\text { percentile }\end{array}$ & $173(89.6)$ & \\
\hline & Overweight $^{1}$ & $15(7.0)$ & \\
\hline & Obese $^{2}$ & $200(93.0)$ & \\
\hline & $\begin{array}{l}\text { SBP-for-age } \\
(\text { Mean } \pm \text { SD) }\end{array}$ & & $1.10 \pm 1.014$ \\
\hline & $\begin{array}{l}\text { DBP-for-age } \\
(\text { Mean } \pm \text { SD) }\end{array}$ & & $0.55 \pm 0.812$ \\
\hline & $\begin{array}{l}\text { Acanthosis } \\
\text { Nigricans }\end{array}$ & $138(63.9)$ & \\
\hline \multirow{4}{*}{$\begin{array}{l}\text { Family } \\
\text { History }\end{array}$} & Obesity & $172(80.0)$ & \\
\hline & Hyperlipidaemia & $117(55.5)$ & \\
\hline & Heart Disease & $88(40.7)$ & \\
\hline & Diabetes & $170(79.4)$ & \\
\hline
\end{tabular}

Table 2: Summary of abnormal results.

\begin{tabular}{|l|l|l|l|}
\hline & & $\begin{array}{l}\text { Frequency } \\
\text { (N) }\end{array}$ & $\begin{array}{l}\text { Percentage } \\
\text { (\%) }\end{array}$ \\
\hline \multirow{7}{*}{} & Elevated HbA1c ${ }^{1}$ & 62 & 31.0 \\
\cline { 2 - 4 } & $\begin{array}{l}\text { Impaired Glucose } \\
\text { Tolerance }\end{array}$ & 15 & 8.2 \\
\cline { 2 - 4 } & Insulin Resistance & 147 & 74.2 \\
\cline { 2 - 4 } & Type 2 DM & 7 & 3.5 \\
\cline { 2 - 4 } & Impaired Fasting & \\
\hline & & 37 & 18.1 \\
\hline${ }^{2}$ Among HbA1c $<6.5$ & & & \\
\hline
\end{tabular}

Results of OGTT were analysed based on the indication of the test (figure 1). Out of the 26 patients who had impaired fasting $(5.6 \mathrm{mmol} / \mathrm{L} \leq \mathrm{FBG}<7 \mathrm{mmol} / \mathrm{L}), 21 \mathrm{had}$ OGTT and $2(9.5 \%)$ showed impaired tolerance. 46 patients, of the 50 who had HbAlc between $5.7 \%$ and $6.5 \%$, had OGTT, and $8(17.4 \%)$ had impaired glucose tolerance. The group who had both high fasting and elevated $\mathrm{HbA} 1 \mathrm{c}$ consisted of 11 patients and all had OGTT. Of that group, 5(45.5\%) had impaired glucose tolerance. No patients were diagnosed with diabetes based on OGTT. 


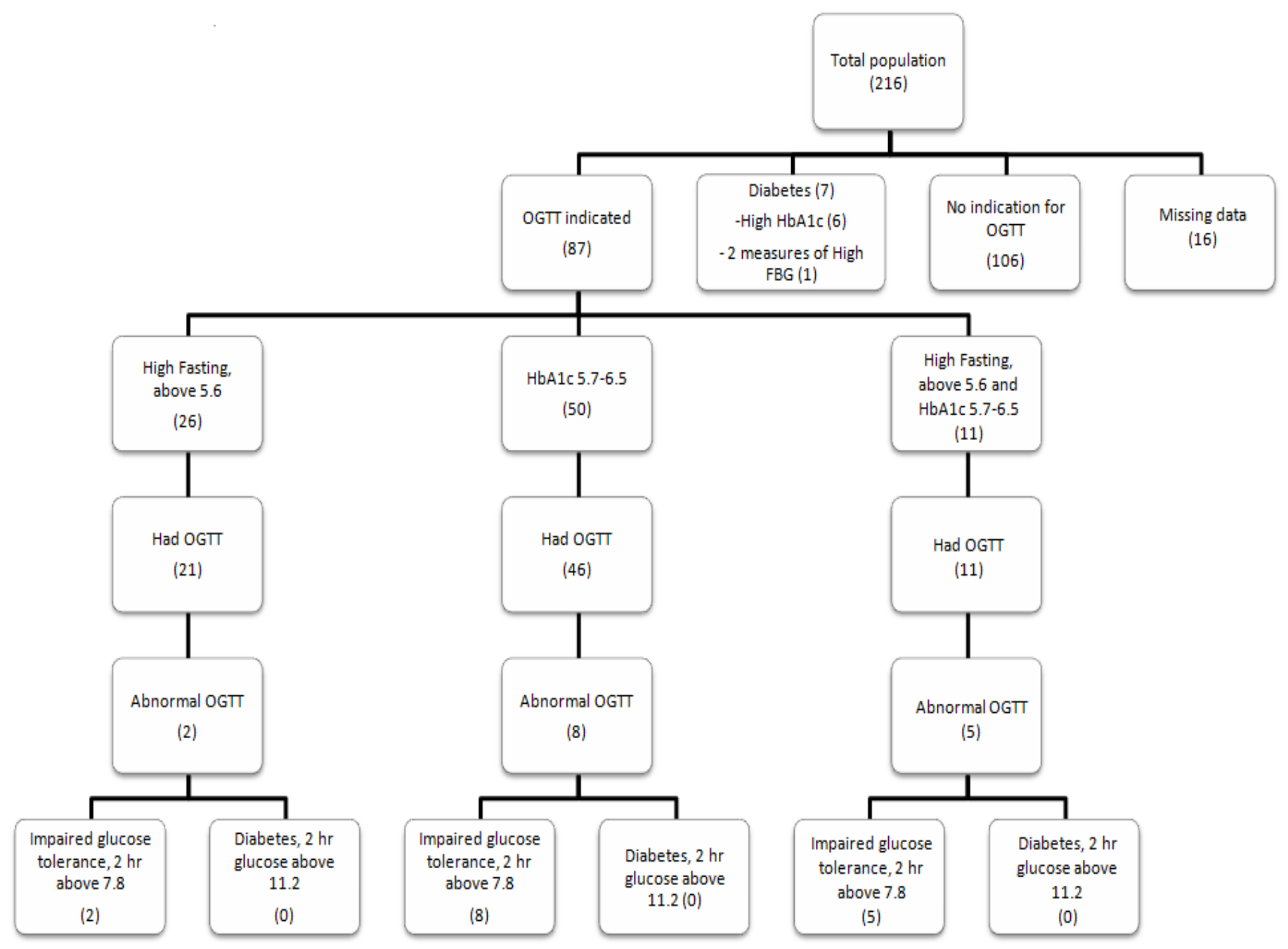

Figure 1: Frequency of diabetes and impaired glucose tolerance.

\section{Results Analysis of Study Parameters}

\section{Insulin resistance}

$74.2 \%$ of the patients had insulin resistance. Relationship of insulin resistance was studied on a bivariate level with age, gender, and standardized height, weight, waist circumference, systolic and diastolic blood pressure. Results showed that an increase in age (years), height-for-age (SD), weight-for-age (SD), and WC-for-age (SD) were all shown to be significantly associated with an increase in insulin resistance (table 4).

Table 3: Bivariate Logistic Regressions of impaired fasting and impaired glucose tolerance with other factors.

\begin{tabular}{|c|c|c|c|c|c|c|}
\hline & \multicolumn{3}{|c|}{ Impaired Fasting } & \multicolumn{3}{|c|}{ Impaired Glucose Tolerance } \\
\hline & \multicolumn{6}{|c|}{$\mathbf{N}=\mathbf{2 0 9}$} \\
\hline Variables & OR & $95 \%$ CI & p-value & OR & $95 \%$ CI & p-value \\
\hline Age & 1.03 & $0.913-1.163$ & 0.625 & 0.98 & $0.824-1.171$ & 0.842 \\
\hline Gender (M) & 1.97 & $0.916-4.255$ & 0.083 & 2.25 & $0.688-7.342$ & 0.180 \\
\hline Height-for-age & 1.39 & $1.002-1.920$ & $0.049^{*}$ & 1.50 & $0.934-2.411$ & 0.093 \\
\hline Weight-for-age & 1.50 & $0.895-2.515$ & 0.123 & 2.50 & $1.176-5.312$ & $0.017 *$ \\
\hline WC-for-age & 0.94 & $0.645-1.374$ & 0.755 & 1.34 & $0.782-2.282$ & 0.289 \\
\hline SBP-for-age & 1.14 & $0.788-1.653$ & 0.485 & 1.37 & $0.790-2.364$ & 0.264 \\
\hline DBP-for-age & 1.09 & $0.695-1.700$ & 0.714 & 0.90 & $0.474-1.717$ & 0.754 \\
\hline
\end{tabular}

${ }^{*}$ p-value $<0.05$ 
Fasting, Glucose Intolerance and Type II Diabetes Mellitus

Table 4: Bivariate Logistic Regressions of insulin resistance and type $2 \mathrm{DM}$ with other factors.

\begin{tabular}{|c|c|c|c|c|c|c|}
\hline & \multicolumn{3}{|c|}{ Type 2 DM } & \multicolumn{3}{|c|}{ Insulin Resistance } \\
\hline & \multicolumn{6}{|c|}{$\mathrm{N}=216$} \\
\hline Variables & OR & $95 \%$ CI & p-value & OR & $95 \%$ CI & p-value \\
\hline Age & 1.15 & $0.890-1.478$ & 0.291 & 1.20 & $1.068-1.354$ & $0.002 *$ \\
\hline Gender (M) & 0.12 & $0.015-1.052$ & 0.056 & 0.67 & $0.349-1.290$ & 0.232 \\
\hline Height-for-age & 1.33 & $0.677-2.609$ & 0.409 & 1.49 & $1.123-1.969$ & $0.006^{*}$ \\
\hline Weight-for-age & 2.67 & $0.918-7.769$ & 0.071 & 2.22 & $1.339-3.683$ & $0.002 *$ \\
\hline WC-for-age & 1.96 & $1.017-3.792$ & $0.044 *$ & 2.13 & $1.359-3.335$ & $0.001 *$ \\
\hline SBP-for-age & 1.37 & $0.619-3.011$ & 0.441 & 1.08 & $0.778-1.496$ & 0.648 \\
\hline DBP-for-age & 1.42 & $0.543-3.697$ & 0.477 & 0.83 & $0.558-1.247$ & 0.376 \\
\hline
\end{tabular}

$*$ p-value $<0.05$

\section{Impaired fasting}

Impaired fasting was analyzed on the sample of non-diabetics $(\mathrm{n}=209) .37(18.1 \%)$ of patients had impaired fasting out of which $11(30.6 \%)$ had abnormal HbAlc defined as HbAlc $\geq 5.7 \%$. Relationship of impaired fasting was studied on a bivariate level with age, gender, and standardized height, weight, waist circumference, systolic and diastolic blood pressure. Results showed that a $1 \mathrm{SD}$ increase in height is significantly associated with an increase in impaired fasting $(\mathrm{OR}=1.39$, $\mathrm{p}$-value $=0.049)($ table 3$)$.

\section{Impaired glucose tolerance}

Impaired glucose tolerance was analyzed on the sample of non-diabetics $(n=209) .15(8.2 \%)$ were diagnosed with impaired glucose tolerance with a $2 \mathrm{hr} B G \geq 7.8 \mathrm{mmol} / \mathrm{L}$. Bivariate logistic regression was conducted to study the association of impaired glucose tolerance based on OGTT results with age, gender, and standardized height, weight, waist circumference, systolic and diastolic blood pressure. Results showed that a 1SD increase in weight is significantly associated with almost threefold increase in impaired glucose tolerance $(\mathrm{OR}=2.50$, $\mathrm{p}$-value $=0.017$ ) (table 3 ; figure 1$)$.

\section{Elevated HbA1c $($ HbA1c $\geq 5.7$ and $<6.5)$}

$62(31.0 \%)$ patients had HbA1c levels at or above $5.7 \%$ and below $6.5 \%$. $11(17.7 \%)$ of those had impaired fasting and one $(1.6 \%)$ had fasting glucose at diabetic level too. Of the 50 $(80.6 \%)$ with high HbA1c and normal fasting, 46 (92.0\%) had OGTT. $8(17.4 \%)$ patients had results indicating impaired glucose tolerance. Of the remaining 12, 11 patients had elevated $\mathrm{HbAlc}$ and impaired fasting and one had elevated HbAlc and 2 consecutive measures of fasting blood glucose indicative of diabetes. All 11 patients had OGTT and $5(45.5 \%)$ had impaired glucose tolerance and none had 2 hours glucose of $11.1 \mathrm{mmol} / \mathrm{L}$.

\section{Diabetes}

$7(3.5 \%)$ patients were diabetics. $6(3.0 \%)$ had HbAlc levels at or above $6.5 \%$ and $1(1.6 \%)$ had 2 consecutive FBG measures above $7 \mathrm{mmol} / \mathrm{L}$. Out of those 6 patients, $3(50.0 \%)$ also had a fasting blood glucose indicative of diabetes $(\geq 7$ $\mathrm{mmol} / \mathrm{L})$.

The relationship between diabetes and the parameters of age, gender, standardized height, weight, waist circumference, systolic and diastolic blood pressure were studied at a bivariate level. Results showed that a $1 \mathrm{SD}$ increase in WC-for-age is significantly associated with the diagnosis of diabetes $(\mathrm{OR}=$ $1.96, \mathrm{p}$-value $=0.044)($ table 4$)$.

\section{Discussion}

Research has witnessed a sudden increase in studies aiming to assess the prevalence of type $2 \mathrm{DM}$ among children and adolescents in the past two decades. However, differences in methodologies adapted and targeted populations make it hard to benchmark results to other studies in the country and worldwide. Several studies have aimed to assess the prevalence of T2DM among patients with diabetes. In the US, $15.9 \%$ of children and adolescent diabetics under the age of 20 recruited between the year 2000 and 2009 were diagnosed with T2DM ${ }^{[15]}$. In 2005 in the UAE, one study showed that $10 \%$ of patients presenting with diabetes had $\mathrm{T} 2 \mathrm{DM}^{[16]}$ and the statistical news reported an overall $9 \%$ prevalence in the emirate of Dubai that same year ${ }^{[17]}$. Another study of children and adolescents from 6 to 18 years of age reported a prevalence of $0.035 \%$ of T2DM among school children in Kuwait ${ }^{[18]}$. Our study targeted overweight and obese children and showed that $3.5 \%$ of patients presenting to an endocrinology clinic in Abu Dhabi were diagnosed with type 2 DM. This percentage is comparable to a study conducted in Sudan in 2013 which showed a T2DM prevalence of $3.86 \%$ in children 11 to 18 years of age attending a pediatric and adolescent diabetic clinic in Khartoum ${ }^{[27]}$. Although highly significant, T2DM prevalence in our study is three-fold lower than a similar study targeting ages of 2 to 18 year olds presenting to a center in Saudi Arabia in $2012^{[20]}$. SEARCH study for diabetes conducted among children and adolescents below 20 years of age showed prevalence of type 2 diabetes to be $15.9 \%$ of all types of diabetes ${ }^{[15]}$.

Our study relied on HbA1c and FBG measures to diagnose diabetes which showed 7 patients had an HbA1c and 1 patient had a fasting glucose at the diabetes range. Relying on different proxies for diabetes yielded differing results among various studies. Using FBG as an indicator for diabetes, this study shows that a total of 4 patients $(1.9 \%)$ had 1 measure of FBG indicative of diabetes. 3 of the 4 patients were also diabetic as per $\mathrm{HbA} 1 \mathrm{c}$, the remaining 1 patient had a consecutive $\mathrm{FBG}$ test done and was shown to be a diabetic based on 2 consecutive measures of FBG. However, using 2 hours glucose reading on OGTT as an indicator for diabetes did not detect any patient with diabetes. These results, in combination with the varying methodologies might explain the discrepancies in diabetes prevalence 


\section{brought about in the literature.}

There is a wealth of data in the literature about overweight and obesity with metabolic syndrome in the pediatric population with prevalence rates ranging between $13.9 \%$ in Italy $^{[28]}$ and $48.8 \%$ in the US ${ }^{[29]}$. Our study showed a relatively high prevalence of insulin resistance among the targeted patients at $74.2 \%$. This is in agreement with several recent studies conducted in Hong-Kong ${ }^{[30]}$ reporting a prevalence of $77 \%$, France $71.8 \%{ }^{[31]}$, and Lebanon $70 \%{ }^{[32]}$ and much higher than Iran reporting a prevalence of $31.8 \%$ among obese adolescents and $23.8 \%$ among obese children ${ }^{[33]}$.

In our study, $8.2 \%$ of non-diabetics had impaired glucose tolerance and $18.1 \%$ had impaired fasting. These figures are higher than those reported by Al Amiri et al. who concluded a lower figure of $5.4 \%{ }^{[34]}$. This could be due to the difference between the patient phenotype at the hospital setting from where our sample was drawn in comparison to the school setting. Our cohort contained a higher weight SDS than those picked from the school setting. Another study conducted on obese children and adolescents aged $4-18$ at a referral hospital in Iran reported even higher prevalence of pre-diabetes at $14.7 \%{ }^{[33]}$. Another oneyear observational study targeting 736 children in an outpatient clinic in Italy showed that $7.7 \%$ had impaired fasting glucose, and $3.18 \%$ had impaired glucose tolerance ${ }^{[35]}$. A cross-sectional survey from China done on 3173 participants showed that the prevalence of prediabetes was $3.3 \%$ in that population ${ }^{[36]}$.

Our study also revealed a significant two-fold increased risk of type II DM with increased waist circumference. This result is in line with a study conducted in Iraq in 2007, which showed through multivariate logistic regression analysis waist circumference to be the most sensitive predictor for T2DM among other anthropometric variables ${ }^{[37]}$. Moreover, our results show that a 1SD increase in height is significantly associated with an increase in impaired fasting and that increases in age (years), height-for-age (SD), weight-for-age (SD), and WC-forage (SD) were all shown to be significantly associated with an increased risks of insulin resistance. It is noteworthy to mention that this study did not account for confounders and possible interactions; results of this crude analysis should be further investigated in similar future studies.

This study has also revealed that there are a substantial number of positive family histories in our cohort. Almost $80 \%$ of the patients had a family history of diabetes and/or obesity, $55.5 \%$ of hyperlipidemia and $40.7 \%$ of heart disease. This is majorly interconnected primarily and secondarily to behavioral, nutritional and environmental factors that have emerged in recent years and contributed to the leading cause of illness, disability and death from obesity and type II diabetes in the Arab countries $^{[22]}$. UAE citizens have slowly shifted towards adopting a sedentary lifestyle that is characterized by unhealthy diets accompanied with a reduction in physical activity. The widespread use of traditional clothing branded by baggy outfits has largely subsidized for children feeling comfortable in their skin with weight gain and parents not being able to clearly notice the weight gain at all. Other factors predisposing Arabs to diabetes in the region is the relatively high percentage of consanguineous marriages and the elevated genetic risk for diabetes ${ }^{[19]}$.

Extensive studies have been tailored towards the genetic predisposition of the Arab population to the development of T2DM. Results from one large study in Jordan, showed a signif- icant correlation between the presence of adenopectin SNP gene and predisposition to type II diabetes in Jordanian population ${ }^{[38]}$. Another genome wide associative study in Lebanon, identified 23 variants on two loci CDKAL1 and TCF7L2, with no relation to sex, age or BMI, that predisposed this population to the development of $\mathrm{T}_{2} \mathrm{DM}^{[39]}$. A genotype study in Tunisia, identified ADIPOQ gene polymorphism as a significant predisposing factor for the development of T2DM in its population ${ }^{[40]}$. Moreover, a study combining both the Lebanese and Tunisian populations also showed that the TCF7L2 gene significantly played a role in the predisposition to type $2 \mathrm{DM}$ in both populations. However, IGF2BP2, KCNJ11, PPAR $\gamma$ and SLC30A8 gene associations with T2DM varied: IGF2BP2and PPAR $\gamma$ association was significant in the Lebanese, but not the Tunisian population, while KCNJ11and SLC30A8 gene associations with T2DM were significant in the Tunisian, but not the Lebanese population. The above highlights the difference in ethnicity predisposition between the Arab populations ${ }^{[41]}$. Considering the significant number of pre diabetes and diabetes patients seen in our study and others and based on the above, it might be worth planning future studies to look at genetic markers for type II diabetes in obese adolescents from the UAE.

Screening for T2DM in obese children has been widely debated for years. The appropriate timing, frequency and tools for screening have not been well defined either.

According to The Yale Pathophysiology of Type 2 Diabetes in Obese Youth Study ${ }^{[42]}$, screening obese children for T2DM is not yielding, particularly when solely relying on A1C as an indicator. As previously mentioned, use of different proxies for diabetes have yielded different results. The Canadian guideline consensus for screening of obese children for T2DM suggests screening high risk children through the use of FBS alone every 2 years and reserving OGTT for those who have numerous risk factors or a standardized BMI at or above $99^{\text {th }}$ percentile $^{[43]}$. Various recent studies are focusing on the use of a combination of A1C and FBS as a screening tool to identify those children eligible for OGTT. This again, explains the discrepancy in the prevalence of diabetes in the literature and the limited capacity to compare research outcomes and benchmark results.

Our study shows that among non-diabetics, $8.2 \%$ had impaired glucose tolerance and $18.1 \%$ had impaired fasting. Moreover, 1 patient (1.6\%) was shown to be diabetic relying on FBG and $0 \%$ relying on OGTT as a proxy for diabetes. Additionally, $50.0 \%$ of those who had Hbalc $\geq 6.5$ had fasting blood glucose $\geq 7 \mathrm{mmol} / \mathrm{L}$. These were not assessed for impaired glucose tolerance. It appears that increase of $\mathrm{HbAlc}$ from non-diabetic to diabetic level is correlated with more than a two-fold increase in impaired fasting. These results might suggest a clearer screening tool using all of the above.

As mentioned in our results, obesity related complications are more frequent than thought in the literature; hence, we need to develop more precise screening tools to accurately detect complications at an early stage. We suggest combining $\mathrm{HbA} 1 \mathrm{C}$ and FBG as a screening tool for type II diabetes in overweight/ obese children who have clinical features of insulin resistance and a family history of metabolic syndrome in a first degree relative. More studies are needed to test the feasibility and cost effectiveness of this screening protocol. 
Acknowledgments: This study was funded by AstraZeneca.

Author Disclosure Statement: No competing financial interests exist.

\section{References}

1. Robinson, D. Killing me sweetly. (2005) Arabian Business-Health 6: 48-53.

2. Malik, M., Bakir, A. Prevalence of overweight and obesity among children in the United Arab Emirates. (2006) Obesity Reviews 8 (1): 15-20.

\section{Pubmed | Crossref | Others}

3. Rocchini, A.P. Childhood obesity and a diabetes epidemic. (2002) N Engl J Med 11: 854-5.

Pubmed | Crossref | Others

4. HAAD School Health Data Reporting, pilot schools 2009/2010.

5. Cook, S., Kavey, R.E. Dyslipidemia and pediatric obesity. (2011) Pediatr Clin North Am 58(6): 1363-1373.

Pubmed | Crossref | Others

6. El-Koofy, N.M., Anwar, G.M., El-Raziky, M.S., et al. The association of metabolic syndrome, insulin resistance and non-alcoholic fatty liver disease in overweight/obese children. (2012) Saudi J Gastroenterol 18(1): 44-49.

Pubmed | Crossref | Others

7. Asfour, M.G., Lambourne, A., Soliman, A., et al. High prevalence of diabetes mellitus and impaired glucose tolerance in the Sultanate of Oman: results of the national survey. (1995) Diabet Med 12: 1122-1125. Pubmed | Crossref | Others

8. Al-Nuaim, R. Prevalence of glucose tolerance in urban and rural communities in Saudi Arabia. (1997) Diabet Med 14(7): 595-602.

Pubmed | Crossref | Others

9. Abdella, N., Khogali, M., Al-Ali, S., et al. Known type 2 diabetes mellitus among the Kuwaiti population: a prevalence study. (1996) Acta Diabetol 33: 145-149.

Pubmed | Crossref | Others

10. MOH/UAE, Ministry of Health, UAE. (2003) Annual Report 2000. Pubmed $\mid$ Crossref $\mid$ Others

11. Ehtisham, S., Barrett, T.G., Shaw, N.J. Type 2 diabetes mellitus in UK children - An emerging problem. (2000) Diabet Med 17(12): 867871.

Pubmed | Crossref | Others

12. Aye, T., Levitsky, L.L. Type 2 diabetes: an epidemic disease in childhood. (2003) Curr Opin Pediatr 15(4): 411-415.

Pubmed | Crossref | Others

13. Rosenbloom, A.L., Joe, J.R., Young, R.S., et al. Emerging epidemic of type 2 diabetes in youth. Diabetes Care 1999 22(2): 345-354.

Pubmed | Crossref | Others

14. Pontiroli, A.E. Type 2 diabetes mellitus is becoming the most common type of diabetes in school children. (2004) Acta Diabetol 41(3): 85-90.

Pubmed | Crossref | Others
15. Pettitt, D.J., Talton, J., Dabelea, D. Prevalence of Diabetes in U.S. Youth in 2009: The SEARCH for Diabetes in Youth Study. (2014) Diabetes Care 37(2): 402-408.

Pubmed | Crossref | Others

16. Punnose, J., Agarwal, A.A., Bin-Uthman, S. Type 2 diabetes mellitus among children and adolescents in Al-Ain: a case series. (2005) East Mediterr Health J 11(4): 788-797.

Pubmed | Others

17. Diabetes Mellitus amongst school age children in Dubai. (2006) Statistical analysis section.

Pubmed $\mid$ Crossref $\mid$ Others

18. Moussa, M.A., AlSaied, M., Abdella, N., et al. Prevalence of Type 2 Diabetes Mellitus among Kuwaiti Children and Adolescents. (2008) Med Princ Pract 17(4): 270-275.

Pubmed | Crossref | Others

19. Abduelkarem, A.R. Childhood obesity and type 2 diabetes: a growing public health challenge in UAE. (2005) Diabetes Voice 50(3): 9-11.

20. Al-Agha, A., Ocheltree, A., Shata, N. Prevalence of hyperinsulinism, type 2 diabetes mellitus and metabolic syndrome among SAUDI overweight and obese pediatric patients. (2012) Minerva Pediatr Dec 64(6): 623-631.

Pubmed | Others

21. Musaiger, A.O., Al-Mannai, M., Al-Lalla, O., et al. Obesity among adolescents in five Arab countries relative to gender and age. (2013) Nutr Hosp 28(6): 1922-1925.

Pubmed | Others

22. Deeb, A., Al-Hazaimeh, R., Attia, S., et al. Energy Intake, Dietary Habits and Life Style in Obese School Children with Dyslipidemia in the UAE. (2015) Int Arch EndocrinolClin Res 1: 001.

Others

23. Centers for Disease Control and Prevention (CDC). National Center for Health Statistics (NCHS). (2008) National Health and Nutrition Examination Survey Data.

Crossref | Others

24. Jackson, R.T., AlHamad, N., Prakash, P., et al. Waist circumference percentiles for Kuwaiti children and adolescents. (2011) Public Health Nutr 14(1): 70-76.

Pubmed | Crossref | Others

25. Matthews, D.R., Hosker, J.P., Rudenski, A.S., et al. Homeostasis model assessment: insulin resistance and beta-cell function from fasting plasma glucose and insulin concentrations in man. (1985) Diabetologia 28(7):412-419.

Pubmed | Crossref | Others

26. American Diabetes Association. Classification and Diagnosis of Diabetes. (2017) Diabetes Care 40(Suppl. 1): S11-S24.

Pubmed | Crossref | Others

27. Osman, H.A., Elsadek, N., Abdullah, M.A. Type 2 diabetes in Sudanese children and adolescents. (2013) Sudan J Paediatr 13(2): 17-23 Pubmed

28. Calcaterra, V., Klersy, C., Muratori, T., et al. Prevalence of the metabolic syndrome in children and adolescents with varying degrees of obesity. (2008) Clin Endocrinol(Oxf) 68(6): 868-872.

Pubmed | Crossref | Others 
29. Dhuper, S., Cohen, H.W., Daniel, J., et al. Utility of the modified ATPIII defined metabolic syndrome and severe obesity as predictors of insulin resistance in overweight children and adolescents: a cross-sectional study. (2007) Cardiovasc Diabetol 6: 4.

Pubmed | Crossref | Others

30. Sung, R.Y., Tong, P.C., Yu, C.W., et al. High prevalence of insulin resistance and metabolic syndrome in overweight/obese preadolescent hong kong chinese children aged 9-12 years. (2003) Diabetes care 26(1): 250-251.

Pubmed | Crossref | Others

31. Druet, C., Dabbas, M., Baltakse, V., et al. Insulin resistance and the metabolic syndrome in obese French children. (2006) Clin Endocrinol (Oxf) 64(6): 672-678.

Pubmed | Crossref | Others

32. Nasreddine, L., Ouaijan, K., Mansour, M., et al. Metabolic Syndrome and Insulin Resistance in Obese Prepubertal Children in Lebanon: A Primary Health Concern. (2010) Ann Nutr Metab 57(2):135-142.

Pubmed | Crossref | Others

33. Ghergherechi, R., Tabrizi, A. Prevalence of impaired glucose tolerance and insulin resistance among obese children and adolescents. (2010) Ther Clin Risk Manag 6: 345-349.

Pubmed | Crossref | Others

34. Al-Amiri, E., Abdullatif, M., Abdulle, A., et al. The prevalence, risk factors, and screening measure for prediabetes and diabetes among Emirati overweight/obese children and adolescents. (2015) BMC Public Health 15: 1298.

Pubmed | Crossref | Others

35. Cambuli, V.M., Incani, M., Pilia, S., et al. Oral glucose tolerance test in Italian overweight/obese children and adolescents results in a very high prevalence of impaired fasting glycaemia, but not of diabetes. (2009) Diabetes Metab Res Rev 25(6): 528-534.

Pubmed | Crossref | Others
36. Zhu, H., Zhang, X., Li, M.Z., et al. Prevalence of Type 2 diabetes and pre-diabetes among overweight or obese children in Tianjin, China. (2013) Diabet Med 30(12):1457-1465.

Pubmed | Crossref | Others

37. Mansour, A.A., Al-Maliky, A.A., Kasem, B., et al. Prevalence of diagnosed and undiagnosed diabetes mellitus in adults aged 19 years and older in Basrah, Iraq. (2014) Diabetes Metab Syndr Obes 7:139-144.

Pubmed | Crossref | Others

38. Alkhateeb, A., Al-Azzam, S., Zyadine, R., et al. Genetic association of adiponectin with type 2 diabetes in Jordanian Arab population. (2013) Gene 512(1): 61-63.

Pubmed | Crossref | Others

39. Ghassibe-Sabbagh, M., Haber, M., Salloum, A.K., et al. T2DM GWAS in the Lebanese population confirms the role of TCF7L2 and CDKAL1 in disease susceptibility. (2014) Sci Rep 4: 7351.

Pubmed | Crossref | Others

40. Mtiraoui, N., Ezzidi, I., Turki, A., et al. Single-nucleotide polymorphisms and haplotypes in the adiponectin gene contribute to the genetic risk for type 2 diabetes in Tunisian Arabs. (2012) Diabetes Res Clin Pract 97(2): 290-297.

Pubmed | Crossref | Others

41. Mtiraoui, N., Turki, A., Nemrc, R., et al. Contribution of common variants of ENPP1, IGF2BP2, KCNJ11, MLXIPL, PPAR $\gamma$, SLC30A8 and TCF7L2 to the risk of type 2 diabetes in Lebanese and Tunisian Arabs. (2012) Diabetes Metab 38(5):444-449.

Pubmed | Crossref | Others

42. Nowicka, P., Santoro, N., Liu, H., et al. Utility of Hemoglobin Alc for Diagnosing Prediabetes and Diabetes in Obese Children and Adolescents. (2011) Diabetes Care 34(6): 1306-1311.

Pubmed | Crossref | Others

43. Canadian Diabetes Association 2013 Clinical Practice Guidelines for the Prevention and Management of Diabetes in Canada. (2013) Can J Diabetes 37(suppl 1): S1-3.

Pubmed | Others
Ommega Online Publishers

Journal Title: Journal of Diabetes and Obesity (JDO)

Journal Short Name: J diabetes Obes
Journal ISSN: 2356-0494

E-mail: diabetes@ommegaonline.com

Website: www.ommegaonline.org 